\title{
Investigation and the Improvement Strategy of the Inquiry Physics Experiment Teaching in Senior High School
}

\author{
Cuixia Zhang ${ }^{1}$, Huanxia Wang ${ }^{1,}$, *, Yu Liu ${ }^{1}$, Jiqiang Jiang ${ }^{3}$ \\ ${ }^{1}$ School of Education, Qufu Normal University, Qufu, China \\ ${ }^{2}$ Chinese Academy of Education Big Data, Qufu, China \\ ${ }^{3}$ School of Mathematical Science, Qufu Normal University, Qufu, China
}

Email address:

wanghx_21cn@163.com (Huanxia Wang)

${ }^{*}$ Corresponding author

To cite this article:

Cuixia Zhang, Huanxia Wang, Yu Liu, Jiqiang Jiang. Investigation and the Improvement Strategy of the Inquiry Physics Experiment Teaching in Senior High School. American Journal of Physics and Applications. Vol. 6, No. 5, 2018, pp. 104-114. doi: 10.11648/j.ajpa.20180605.11

Received: September 11, 2018; Accepted: September 26, 2018; Published: October 25, 2018

\begin{abstract}
In accordance with the international trend, the new round of curriculum reform of basic education in China vigorously advocates inquiry teaching. Experiment plays an important role in physics. However, experiments have not been paid much attention in the past, so it is necessary to analyze how to carry out inquiry experiment teaching and investigate the current implementation status of inquiry-based experiment teaching. In this paper, literature research and questionnaire survey are conducted to investigate the students from the aspects of implementation conditions, implementation intention, implementation process and implementation effect of the inquiry physics experiment teaching. The results show that the present situation of physical inquiry experiment teaching is not optimistic. Although the overwhelming majority of students have positive intention to carry out the physical inquiry experiment, there are many problems in the implementation condition, implementation process and implementation effect of the physical inquiry experiment teaching. And it is in some degree trapped in the practical dilemma of formalism, which needs further improvement and perfection. Therefore, in order to promote the further optimization of exploratory experimental teaching, it is firstly suggested to provide multiparty support for the effective implementation of exploratory experiment teaching. Then, the operational examination is considered to be added in high-interest examinations. Finally, the physics teachers need to improve their professional quality.
\end{abstract}

Keywords: Inquiry Experiment Teaching, Physical Curriculum Standards, Evaluation of Operational Experiment Test

\section{Introduction}

Curriculum reform in various countries in the world has advocated scientific inquiry. Inquiry teaching has become a trend and is an indispensable means to cultivate modern talents. In accordance with the international trend, the new round of curriculum reform of basic education in China vigorously advocates inquiry teaching. The new physics curriculum reform attaches great importance to exploratory experiment teaching as experiment plays an important role in physics. The physical curriculum standards fully attach importance to the cultivation of students' scientific inquiry and experimental ability. In the content standard part, the basic requirements of scientific inquiry and experimental ability are stipulated. As the important content of the teaching, the subject of inquiry activities in the common required module and elective module is reflected in the exploration of subject items and activity suggestions [1]. Different versions of physics textbooks regard the implementation of the new curriculum concept and the cultivation of students' scientific inquiry ability as the basic starting point. And they emphasize the cultivation of students' ability to explore thinking and the design of scientific inquiry experiments by exploring the materials around them [2]. From the subject of inquiry, the requirements of the textbook and the curriculum standards are consistent. For the subject of the curriculum standards, the textbook is basically presented in the way of experimental inquiry, and provides a more detailed plan and activity guidance [3]. Curriculum standards and textbooks attach great importance to the cultivation of students' ability of experiment 
and inquiry. What is the current situation of the physical inquiry experiment teaching in teaching practice? In view of this problem, we have carried out extensive research.

\section{Research Methods and Processes}

\subsection{Research Methods}

Based on the literature research of inquiry experimental teaching, the Questionnaire on the Implementation Status of Physical Inquiry Experimental Teaching is designed with reference to the compilation method of personality test in psycho metrics [4]. The questionnaire consists of 11 test questions, which involve four dimensions of implementation conditions, implementation intention, implementation process and implementation effect of physics inquiry experimental teaching. It includes the degree of attention to the physical inquiry experiment teaching activities, the instrument and equipment of the experiment, the degree of opening of the laboratory, the competence of the teacher to the inquiry experiment teaching, the students' interest in the inquiry experiment, the students' performance in the experiment process, the measures taken when the experiment encountered difficulties, the effect of experimental activities and whether the enhancement of inquiry ability is obvious. The questionnaire was pretested and the results showed that the questionnaire had good reliability and validity.

\subsection{Research Process}

In this study, four senior high schools $(A, B, C, D)$ in different regions of Shandong Province in China are selected as the survey subjects. Every high school selects students from two classes in grade one and each class in liberal arts and science in grade two. The specific distribution of samples is shown in Table 1. 781 questionnaires are distributed, 778 questionnaires are collected, and 755 valid questionnaires are issued with an effective rate of $96.67 \%$. In order to make students have a clear understanding of the difference between inquiry experiment and traditional experiment, the author asks the physics teachers from four schools to explain in detail the characteristics of the inquiry experiment and the difference between the inquiry experiment and the verification experiment. At the same time, the exact meaning and difference of the seven major inquiry elements (Raising questions, Supposing and Assuming, Formulating Plans and Designing Experiments, Conducting Experiments and Collecting Evidence, Analyzing and Demonstrating, Evaluating, Communicating and Cooperating) are explained in detail according to the requirements of scientific inquiry and physical experiment in the general high school physics curriculum standard.

Table 1. Distribution of student samples.

\begin{tabular}{|c|c|c|c|c|}
\hline & $\begin{array}{l}\text { Number of } \\
\text { questionnaires issued }\end{array}$ & $\begin{array}{l}\text { Number of questionnaires } \\
\text { returned }\end{array}$ & $\begin{array}{l}\text { Number of valid } \\
\text { questionnaires }\end{array}$ & $\begin{array}{l}\text { Ratio of valid } \\
\text { questionnaires }\end{array}$ \\
\hline A School & 248 & 246 & 240 & $96.77 \%$ \\
\hline No. 1 class in senior one & 63 & 63 & 62 & $98.41 \%$ \\
\hline No. 2 class in senior one & 60 & 58 & 56 & $93.33 \%$ \\
\hline one liberal arts class in senior two & 64 & 64 & 62 & $96.88 \%$ \\
\hline one science class in senior two & 61 & 61 & 60 & $98.36 \%$ \\
\hline B School & 172 & 172 & 167 & $97.09 \%$ \\
\hline No. 1 class in senior one & 43 & 43 & 42 & $97.67 \%$ \\
\hline No. 2 class in senior one & 42 & 42 & 41 & $97.62 \%$ \\
\hline one liberal arts class in senior two & 44 & 44 & 42 & $95.45 \%$ \\
\hline one science class in senior two & 43 & 43 & 42 & $97.67 \%$ \\
\hline C School & 193 & 193 & 187 & $96.89 \%$ \\
\hline No. 1 class in senior one & 50 & 50 & 48 & $96.00 \%$ \\
\hline No. 2 class in senior one & 50 & 50 & 48 & $96.00 \%$ \\
\hline one liberal arts class in senior two & 46 & 46 & 45 & $97.83 \%$ \\
\hline one science class in senior two & 47 & 47 & 46 & $97.87 \%$ \\
\hline D School & 168 & 167 & 161 & $95.83 \%$ \\
\hline No. 1 class in senior one & 43 & 43 & 41 & $95.35 \%$ \\
\hline No. 2 class in senior one & 42 & 42 & 40 & $95.24 \%$ \\
\hline one liberal arts class in senior two & 40 & 40 & 39 & $97.50 \%$ \\
\hline one science class in senior two & 43 & 42 & 41 & $95.35 \%$ \\
\hline Subtotal & 781 & 778 & 755 & $96.67 \%$ \\
\hline
\end{tabular}

\section{Results}

The students are investigated from four dimensions: the implementation conditions, the implementation intention, the implementation process and the implementation effect of physical inquiry experiment teaching. The results of the survey are as follows.

\subsection{The Investigation Results and Analysis of the Implementation Conditions of Physical Inquiry Experiment Teaching}

The questions from No.1-No.5 are designed to investigate the importance and implementation conditions of inquiry experiment teaching in schools. The specific questions are set 
as follows.

1. Does your school attach importance to teaching activities about physics inquiry experiment?

A. Extremely B. Quite a bit C. Fair D. A little bit E. Not at all

2. As shown in Table 2, does your school offer enough equipment to carry out physical inquiry experiment?

A. Extremely B. Quite a bit C. Fair D. A little bit E. Not at all

Table 2. The physical equipment provided in your school.

\begin{tabular}{lllll} 
A & B & C & D & E \\
\hline
\end{tabular}

2.1 Physics lab

2.2 Physical experiment apparatus
3. How open is the physics laboratory in your school?

A. Extremely B. Quite a bit C. Fair D. A little bit E. Not at all

4. Do you have easy access to the library or newspaper room?

A. Extremely B. Quite a bit C. Fair D. A little bit E. Not at all

5. Do you think your physics teacher is competent for Physics Inquiry Experiment Teaching in high school?

A. Extremely B. Quite a bit C. Fair D. A little bit E. Not at all

The findings of implementation conditions of physical inquiry experiment teaching are shown in Table 3 . The data in the form is shown in percentage.

Table 3. The Investigation results of the implementation conditions of physical inquiry experiment teaching.

\begin{tabular}{|c|c|c|c|c|c|c|}
\hline Question Number & Option & Student Samples & A School & B School & C School & D School \\
\hline \multirow{5}{*}{1} & $\mathrm{~A}$ & 7.81 & 13.75 & 1.79 & 1.07 & 13.05 \\
\hline & $\mathrm{B}$ & 47.95 & 39.17 & 62.88 & 57.75 & 34.16 \\
\hline & $\mathrm{C}$ & 33.11 & 32.50 & 34.73 & 27.27 & 39.13 \\
\hline & $\mathrm{D}$ & 7.95 & 8.33 & 0.00 & 12.83 & 9.94 \\
\hline & $\mathrm{E}$ & 3.18 & 6.25 & 0.60 & 1.07 & 3.73 \\
\hline \multirow{4}{*}{2.1} & A & 27.95 & 16.25 & 70.66 & 5.35 & 27.33 \\
\hline & $\mathrm{B}$ & 49.80 & 64.17 & 28.14 & 52.94 & 47.21 \\
\hline & $\mathrm{D}$ & 7.68 & 7.92 & 0.00 & 16.04 & 5.59 \\
\hline & $\mathrm{E}$ & 3.31 & 3.33 & 0.00 & 7.49 & 1.86 \\
\hline \multirow{5}{*}{2.2} & A & 10.99 & 13.33 & 1.79 & 6.41 & 22.36 \\
\hline & $\mathrm{B}$ & 45.83 & 61.67 & 28.14 & 41.18 & 45.96 \\
\hline & $\mathrm{C}$ & 31.26 & 12.50 & 69.46 & 27.81 & 23.60 \\
\hline & $\mathrm{D}$ & 6.62 & 8.75 & 0.00 & 12.30 & 3.73 \\
\hline & $\mathrm{E}$ & 5.17 & 3.75 & 0.00 & 12.30 & 4.35 \\
\hline \multirow{4}{*}{3} & A & 11.92 & 10.42 & 0.60 & 23.53 & 12.42 \\
\hline & $\mathrm{C}$ & 41.85 & 28.75 & 93.41 & 22.46 & 30.43 \\
\hline & D & 11.66 & 12.92 & 0.60 & 19.25 & 12.42 \\
\hline & $\mathrm{E}$ & 10.07 & 10.42 & 0.60 & 17.11 & 11.18 \\
\hline \multirow{5}{*}{4} & A & 10.73 & 10.42 & 3.59 & 8.56 & 21.11 \\
\hline & B & 45.69 & 27.50 & 82.63 & 45.45 & 34.78 \\
\hline & $\mathrm{C}$ & 21.06 & 30.41 & 13.77 & 15.51 & 21.12 \\
\hline & D & 11.13 & 11.67 & 0.00 & 18.72 & 13.05 \\
\hline & $\mathrm{E}$ & 11.39 & 20.00 & 0.00 & 11.76 & 9.94 \\
\hline \multirow{5}{*}{5} & A & 50.60 & 31.67 & 95.81 & 24.60 & 62.11 \\
\hline & B & 30.33 & 47.08 & 3.59 & 33.69 & 29.19 \\
\hline & $\mathrm{C}$ & 13.64 & 12.08 & 0.00 & 34.76 & 5.59 \\
\hline & D & 3.71 & 5.42 & 0.60 & 5.88 & 1.86 \\
\hline & E & 1.72 & 3.75 & 0.00 & 1.07 & 1.24 \\
\hline
\end{tabular}

As is shown in Table 3, students believe that the implementation conditions of physical inquiry experiment teaching need to be improved. In terms of the overall situation of the four schools, $55.76 \%$ of the students believe that their schools attach importance to physical inquiry experiment teaching activities. $77.75 \%$ of the students think that the physical laboratory in the school is well equipped. $56.82 \%$ of the students insist that the physical experimental instruments in the school are adequately equipped. $56.42 \%$ of the students maintain that they can easily go to the library or the reference room and so on. Most of the students $80.93 \%$ hold that physics teachers are competent for the teaching of physics inquiry experiment. However, $63.58 \%$ students think that the physics laboratory in their school is not open enough. Nearly half of the students believe that their school does not pay attention to physical inquiry experimental teaching activities. $43.05 \%$ of the students think that the school physics laboratory equipment is inadequate, and $43.58 \%$ of the students believe they can't easily go to the library or the reference room.

The results of the four schools are as follows. The percentage of students in four schools considering that their schools attach importance to physical inquiry experiment teaching activities are 52.92, 64.67, 58.82 and 47.21 respectively and basically fluctuate in 50 . The percentage of students who believe that their physics laboratory is adequately equipped are $80.42,98.80,58.29$ and 74.54 respectively, indicating that three schools are adequately equipped with physics laboratories and one school is weak. 
The percentage of students who believe that their school has sufficient physical experimental instruments are 75, 29.93, 47.59 and 68.32 respectively. It is obvious that the physical experimental instruments in A and D schools are well equipped, the $\mathrm{C}$ school is weak, and the $\mathrm{B}$ school needs to increase the physical experimental instruments. The percentage of students believing the opening degree of the laboratory satisfactory is $47.92,5.39,41.18$ and 45.96 respectively. It is obvious that physical laboratory in A school, $\mathrm{C}$ school and D school are not open enough. And it is urgent for B school to enhance the openness of the physical laboratory as it is extremely weak. The percentage of the people who think that they can easily go to the library or the reference room are 37.92, 86.22, 54.01, and 55.89. It can be seen that only students in B school can easily inquire the data, and none of the students in the other three schools can conveniently inquire the data. The percentage of physical teachers who are qualified for physical inquiry teaching are $78.75,99.40,58.29$ and 91.30 , indicating that students of three schools believe that physics teachers are capable of physical inquiry teaching. Only students of school $\mathrm{C}$ believe that physics teachers need to improve their ability of physics exploratory experimental teaching.

\subsection{The Investigation Results and Analysis of the Implementation Intention of Physical Inquiry Experiment Teaching}

The questions from No. 6 - No. 7 are designed to investigate students' attitudes towards physics inquiry experiments.

6. Are you interested in physics inquiry experiments?

A. Extremely B. Quite a bit C. Fair D. A little bit E. Not at all

7. Are you willing to do physical inquiry experiments?

A. Extremely B. Quite a bit C. Fair D. A little bit E. Not at all

The investigation results of the implementation intention of physical inquiry experiment teaching are shown in Table 4. The data in the form is shown in percentage.

Table 4. The investigation results of the implementation intention of physical inquiry experiment teaching.

\begin{tabular}{|c|c|c|c|c|c|c|}
\hline Question Number & Option & Student Samples & A School & B School & C School & D School \\
\hline \multirow{4}{*}{6} & $\mathrm{~A}$ & 29.53 & 31.25 & 2.39 & 46.52 & 35.40 \\
\hline & B & 37.35 & 47.92 & 26.95 & 29.94 & 40.99 \\
\hline & $\mathrm{C}$ & 27.02 & 12.92 & 70.06 & 17.11 & 14.91 \\
\hline & $\mathrm{E}$ & 2.38 & 3.33 & 0.60 & 0.00 & 5.59 \\
\hline \multirow{4}{*}{7} & A & 30.20 & 38.33 & 2.99 & 27.80 & 49.07 \\
\hline & $\mathrm{B}$ & 36.82 & 40.42 & 55.09 & 19.25 & 32.92 \\
\hline & $\mathrm{D}$ & 6.23 & 4.58 & 0.00 & 16.58 & 3.11 \\
\hline & $\mathrm{E}$ & 1.46 & 1.25 & 0.60 & 1.60 & 2.48 \\
\hline
\end{tabular}

As is shown in Table 4, students have positive intention to carry out physics inquiry experiment teaching. As far as the overall situation of the four schools is concerned, $66.88 \%$ of students are interested in physical inquiry experiments, and $67.02 \%$ of students are willing to do physical inquiry experiments. Only a small number of students $(6.09 \%)$ clearly show that they are not interested in physical inquiry-based experiments, while $7.68 \%$ of students clearly indicate that they are not willing to do physical inquiry experiments.

The results of the four schools are as follows. The percentage of students interested in physical inquiry experiments in four schools are 79.17, 29.34, 76.46 and 76.39, and most of the students in three schools are interested in physical inquiry experiments. Besides, the students in school $\mathrm{B}$ are not interested in physical inquiry experiments to some extent. The percentage of people willing to do physical inquiry experiments are 78.75, 58.08, 47.05 and 81.99 . So most of the students in A and D school are willing to do physical inquiry experiments, and about half of the students in B and C school are capable of doing physical inquiry experiments. It is worth mentioning that in the four schools surveyed, most of the students in B school are not interested in the physical inquiry experiment while most students from the other three schools express strong interest, which makes a sharp contrast. Based on the survey results of the implementation conditions of the physics inquiry experiment teaching in the front, the author interviews the students in B school. The main reason that the students are not interested in the physical inquiry experiment is that the physical laboratory equipment is very inadequate although the school has a physical laboratory. There are only a few experimental instruments necessary for validation experiments and they are obsolete. Moreover, the opening degree of the physics laboratory is very poor, and students' physics experiment courses are often replaced by theoretical courses and review courses. At other times of the non-physical experiment class, students have no opportunity to go to the laboratory for research or independently design exploratory experiments. In this way, a vicious circle has been formed, which has greatly weakened the interest of students in physics exploratory experiments in B school.

\subsection{The Investigation Results and Analysis of the Implementation Process of Physical Inquiry Experiment Teaching}

Questions from No. 8 to No. 10 are to investigate the implementation process of physical inquiry experiment. It consists of the number of team members, the performance in the process of physical inquiry experiment (can be divided into seven elements of inquiry), and the performance of dealing with difficulty in carrying out physical inquiry experiments. 
8. When you do physical inquiry, how many people do you have in a group?

A. 1 B. 2 C. $3-4$ D. $5-8$ E. 9
9. As shown in Table 5, do you think you have performed well in conducting physics inquiry experiments?

A. Extremely B. Quite a bit C. Fair D. A little bit E. Not at all.

Table 5. The basic ability of conducting physics inquiry experiment.

\begin{tabular}{l|l|l|}
\hline & A & B \\
\hline 9.1 Raising Questions & \\
9.2 Supposing and Assuming & \\
9.3 Formulating Plans and Designing Experiments & \\
9.4 Conducting Experiments and Collecting Evidence & \\
9.5 Analyzing and Demonstrating & \\
9.6 Evaluating & \\
9.7 Communicating and Cooperating & \\
\hline
\end{tabular}

10. As shown in Table 6, what are you going to do when you have difficulty in conducting physics inquiry experiments?

A. Agree extremely B. Agree quite a bit C. Fair D. Agree a little bit E. Not agree at all

Table 6. What are you going to do when you have difficulty in conducting physics inquiry experiments?

\begin{tabular}{|c|c|c|c|c|c|}
\hline & $\mathbf{A}$ & B & C & D & $\mathbf{E}$ \\
\hline $\begin{array}{l}\text { 10.1 Improvement plan and plan } \\
\text { 10.2 Learn from experience and lessons bit by bit } \\
\text { 10.3 Discuss new problems and difficulties with others } \\
\text { 10.4 Focus on the progress and results of other groups }\end{array}$ & & & & & \\
\hline
\end{tabular}

The investigation results of the implementation process of physical inquiry experiment teaching are shown in Table 7 . The data in the form is shown in percentage.

Table 7. The investigation results of the implementation process of physical inquiry experiment teaching.

\begin{tabular}{|c|c|c|c|c|c|c|}
\hline Question Number & Option & Student Samples & A School & B School & C School & D School \\
\hline \multirow{5}{*}{8} & $\mathrm{~A}$ & 3.31 & 7.08 & 0.60 & 0.00 & 4.35 \\
\hline & B & 20.79 & 21.25 & 4.19 & 1.07 & 60.24 \\
\hline & $\mathrm{C}$ & 66.62 & 54.58 & 93.41 & 93.58 & 25.47 \\
\hline & $\mathrm{D}$ & 7.42 & 12.50 & 1.79 & 5.35 & 8.07 \\
\hline & $\mathrm{E}$ & 1.72 & 4.17 & 0.00 & 0.00 & 1.86 \\
\hline \multirow{5}{*}{9.1} & A & 11.92 & 20.42 & 1.79 & 4.28 & 18.64 \\
\hline & B & 33.11 & 41.66 & 16.17 & 32.62 & 38.51 \\
\hline & $\mathrm{C}$ & 43.97 & 27.50 & 80.84 & 40.11 & 34.78 \\
\hline & $\mathrm{D}$ & 8.74 & 8.33 & 1.20 & 18.72 & 5.59 \\
\hline & $\mathrm{E}$ & 2.12 & 2.08 & 0.00 & 3.74 & 2.48 \\
\hline \multirow{5}{*}{9.2} & A & 12.85 & 21.67 & 1.20 & 10.16 & 14.90 \\
\hline & $\mathrm{B}$ & 43.71 & 48.33 & 29.94 & 49.20 & 44.72 \\
\hline & $\mathrm{C}$ & 36.29 & 20.83 & 67.66 & 29.95 & 34.16 \\
\hline & $\mathrm{D}$ & 5.69 & 7.50 & 1.19 & 7.49 & 5.59 \\
\hline & $\mathrm{E}$ & 1.46 & 1.67 & 0.00 & 3.21 & 0.62 \\
\hline \multirow{5}{*}{9.3} & A & 12.98 & 20.83 & 1.79 & 6.42 & 20.50 \\
\hline & B & 37.62 & 47.50 & 20.36 & 42.78 & 34.78 \\
\hline & $\mathrm{C}$ & 40.40 & 23.33 & 77.84 & 31.02 & 37.89 \\
\hline & D & 8.08 & 7.08 & 0.00 & 19.79 & 4.35 \\
\hline & $\mathrm{E}$ & 0.93 & 1.25 & 0.00 & 0.00 & 2.48 \\
\hline \multirow{5}{*}{9.4} & A & 21.72 & 22.09 & 3.59 & 36.90 & 22.36 \\
\hline & B & 36.16 & 47.92 & 34.73 & 18.18 & 40.99 \\
\hline & $\mathrm{C}$ & 33.51 & 20.42 & 60.48 & 28.88 & 30.44 \\
\hline & D & 6.09 & 7.50 & 1.20 & 9.62 & 4.97 \\
\hline & $\mathrm{E}$ & 2.52 & 2.08 & 0.00 & 6.42 & 1.24 \\
\hline \multirow{5}{*}{9.5} & A & 14.97 & 25.84 & 2.99 & 3.74 & 24.23 \\
\hline & B & 40.40 & 44.17 & 14.37 & 62.03 & 36.65 \\
\hline & $\mathrm{C}$ & 38.41 & 24.58 & 81.44 & 21.93 & 33.54 \\
\hline & D & 5.43 & 4.17 & 1.20 & 11.76 & 4.35 \\
\hline & $\mathrm{E}$ & 0.66 & 1.25 & 0.00 & 0.00 & 1.24 \\
\hline \multirow{5}{*}{9.6} & A & 20.26 & 22.08 & 2.40 & 32.08 & 22.36 \\
\hline & B & 34.17 & 46.25 & 8.38 & 34.76 & 42.24 \\
\hline & $\mathrm{C}$ & 37.08 & 22.91 & 85.03 & 19.79 & 28.57 \\
\hline & D & 6.76 & 6.67 & 4.19 & 10.70 & 4.97 \\
\hline & $\mathrm{E}$ & 1.59 & 1.66 & 0.00 & 2.67 & 1.86 \\
\hline 9.7 & A & 24.50 & 26.66 & 23.95 & 13.37 & 34.78 \\
\hline
\end{tabular}




\begin{tabular}{|c|c|c|c|c|c|c|}
\hline Question Number & Option & Student Samples & A School & B School & C School & D School \\
\hline \multirow{9}{*}{10.1} & B & 40.93 & 51.25 & 13.17 & 54.01 & 39.13 \\
\hline & $\mathrm{C}$ & 28.74 & 15.42 & 62.87 & 20.32 & 22.98 \\
\hline & $\mathrm{D}$ & 4.50 & 4.58 & 0.00 & 10.69 & 1.86 \\
\hline & $\mathrm{E}$ & 1.19 & 1.66 & 0.00 & 1.60 & 1.24 \\
\hline & A & 14.83 & 23.75 & 0.00 & 9.09 & 23.60 \\
\hline & B & 41.19 & 54.58 & 0.00 & 54.55 & 48.45 \\
\hline & $\mathrm{C}$ & 40.14 & 17.50 & 99.40 & 29.42 & 24.85 \\
\hline & $\mathrm{D}$ & 3.18 & 2.92 & 0.60 & 6.95 & 1.86 \\
\hline & E & 0.66 & 1.25 & 0.00 & 0.00 & 1.24 \\
\hline \multirow{5}{*}{10.2} & A & 23.71 & 22.92 & 28.74 & 11.76 & 33.55 \\
\hline & $\mathrm{B}$ & 52.32 & 53.75 & 68.26 & 38.50 & 49.69 \\
\hline & $\mathrm{C}$ & 20.00 & 19.17 & 2.99 & 41.71 & 13.66 \\
\hline & $\mathrm{D}$ & 2.38 & 2.91 & 0.00 & 4.82 & 1.24 \\
\hline & $\mathrm{E}$ & 1.46 & 0.83 & 0.00 & 3.21 & 1.86 \\
\hline \multirow{5}{*}{10.3} & A & 32.72 & 28.33 & 29.94 & 37.97 & 36.03 \\
\hline & $\mathrm{B}$ & 49.14 & 50.42 & 67.07 & 32.62 & 47.83 \\
\hline & $\mathrm{C}$ & 13.24 & 13.75 & 2.99 & 21.39 & 13.66 \\
\hline & $\mathrm{D}$ & 3.71 & 5.42 & 0.00 & 6.42 & 1.86 \\
\hline & E & 1.19 & 2.08 & 0.00 & 1.61 & 0.62 \\
\hline \multirow{5}{*}{10.4} & A & 20.40 & 30.42 & 13.17 & 8.02 & 27.33 \\
\hline & B & 53.64 & 49.58 & 84.43 & 36.90 & 47.20 \\
\hline & $\mathrm{C}$ & 11.52 & 10.83 & 2.40 & 17.11 & 15.53 \\
\hline & $\mathrm{D}$ & 10.99 & 5.00 & 0.00 & 31.55 & 7.45 \\
\hline & $\mathrm{E}$ & 3.05 & 4.16 & 0.00 & 4.82 & 2.48 \\
\hline
\end{tabular}

As can be seen from Table 7, students think that the implementation process of physics inquiry experiment teaching is not good enough. In terms of the overall situation of the four schools, the survey results show that more than half (54.47\%) of the students think that they are not good at Raising Questions well. $43.44 \%$ of students think that their Supposing and Assuming are not good enough. $49.41 \%$ students insist that they are not expert in Formulating Plans and Designing Experiments. $42.12 \%$ students don't think that they excel at Conducting Experiments and Collecting Evidence. $44.63 \%$ students think that their Analyzing and Demonstrating are not excellent enough. $45.56 \%$ students think that their Evaluating are not good enough. It is remarkable that most of the students $(65.43 \%)$ think that they do well in Communicating and Cooperating. What's more, it is gratifying that most students will take positive measures when they are confronted with difficulties in carrying out physics inquiry experiments. $56.03 \%$ of the students will improve their plans and programs. $76.03 \%$ of the students will draw experiences and lessons bit by bit. $74.04 \%$ of the students will pay attention to the progress and results of other groups. And the vast majority (81.86\%) of students will discuss with others the newly discovered problems and difficulties.

The analysis results of the four schools are as follows. The percentage of people who think they Raising Questions well are $62.08,17.96,36.90$ and 57.15 , which shows that students in A school and D school are a little better. Students in B school and C school think they are poor at Raising Questions. The percentage of people who hold they Supposing and Assuming well was $70.00,31.14,59.36$ and 59.62 respectively. It can be seen that students in school B think their performance in Supposing and Assuming is poor, while students in the other three schools are in good condition. The percentages of people who think they perform well in Formulating Plans and Designing Experiments are 68.33, 22.15, 49.20 and 55.28 respectively. It can be seen that students of school B think that they have poor performance in Formulating Plans and Designing Experiments, students of school A think that they have better performance, and students of school $\mathrm{C}$ and school $\mathrm{D}$ think that they are in general performance. The percentages of people who think they perform well in Conducting Experiments and Collecting Evidence are 70.01, 38.32, 55.08 and 63.35 respectively. Thus, the students in school B think they have poor performance in Conducting Experiments and Collecting Evidence, students in school A think they have better performance, and students in school C and D think they do slightly better. The percentages of people who consider themselves Analyzing and Demonstrating to perform well are $70.01,17.36,65.77$ and 60.88 respectively. It can be seen that students in school B think they have a poor performance in Analyzing and Demonstrating, students in A school think they have a wonderful performance, and students in school C and D think they have a little better performance. The percentage of people who rate themselves in Evaluating as outstanding is $68.33,10.78,66.84$ and 64.60 respectively. It can be seen that the students of school B think their Evaluating is extremely poor, and the students of other three schools think their performance is satisfactory. The percentage of people who think they have good Communicating and Cooperating is $77.91,37.12,67.38$ and 73.91 respectively. It can be seen that students of school B think they have poor performance in Communicating and Cooperating, and the students of other three schools think their performance is pretty good. From the above, the vast majority of students in school B believe that they can easily go to the library or the reference room. However, since inquiry experiments are not theoretical, students must design and operate independently. In B school, importance isn't attached to physics inquiry experiments, and the experimental instruments are very inadequate, lacking of exploratory experimental instruments and non-opening of the 
laboratory. As a result, the students in B school think that they perform poorly in all aspects of the implementation of the inquiry experiment, obviously lagging behind the performance of the other three schools.

\subsection{The Investigation Results and Analysis of the Implementation Effect of Physical Inquiry Experiment Teaching}

Questions 11 to 12 investigate the overall effect of students' physical inquiry experiment activities and the improvement of seven inquiry abilities. The questions are as follows.

11. do you have good effects in conducting physical inquiry experiments?

A. Extremely B. Quite a bit C. Fair D. A little bit E. Not at all

12. As shown in Table 8, do you improve your ability to explore through physical inquiry experiments?

A. Extremely B. Quite a bit C. Fair D. A little bit E. Not at all

Table 8. Ability to explore.

\begin{tabular}{l|l|l}
\hline & A & B \\
\hline 12.1 Ability to raising questions & & D \\
12.2 Ability to supposing and assuming & \\
12.3 Ability to formulating plans and designing experiments & \\
12.4 Ability to conducting experiments and collecting evidence & \\
12.5 Ability to analyzing and demonstrating & \\
12.6 Ability to evaluating & \\
12.7 Ability to communicating and cooperating & \\
\hline
\end{tabular}

The investigation results of the implementation effect of physical inquiry experiment teaching are shown in Table 9 . The data in the form is shown in percentage.

Table 9. The investigation results of the implementation effect of physical inquiry experiment teaching.

\begin{tabular}{|c|c|c|c|c|c|c|}
\hline Question Number & Option & Student Samples & A School & B School & C School & D School \\
\hline \multirow{5}{*}{11} & $\mathrm{~A}$ & 11.26 & 18.34 & 1.20 & 8.56 & 14.28 \\
\hline & $\mathrm{B}$ & 44.37 & 54.16 & 23.95 & 43.32 & 52.17 \\
\hline & $\mathrm{C}$ & 36.82 & 20.00 & 74.85 & 33.69 & 26.09 \\
\hline & $\mathrm{D}$ & 4.90 & 3.75 & 0.00 & 13.37 & 1.86 \\
\hline & $\mathrm{E}$ & 2.65 & 3.75 & 0.00 & 1.07 & 5.59 \\
\hline \multirow{4}{*}{12.1} & $\mathrm{~A}$ & 14.44 & 20.83 & 0.00 & 13.90 & 20.50 \\
\hline & $\mathrm{C}$ & 39.20 & 19.58 & 88.02 & 34.76 & 22.98 \\
\hline & $\mathrm{D}$ & 1.72 & 3.33 & 0.00 & 0.53 & 2.49 \\
\hline & $\mathrm{E}$ & 3.05 & 3.75 & 0.00 & 4.82 & 3.10 \\
\hline \multirow{4}{*}{12.2} & A & 14.44 & 22.92 & 2.99 & 6.95 & 22.36 \\
\hline & $\mathrm{B}$ & 34.70 & 46.25 & 19.76 & 19.79 & 50.31 \\
\hline & $\mathrm{C}$ & 44.37 & 23.75 & 76.05 & 61.50 & 22.36 \\
\hline & $\mathrm{D}$ & 4.24 & 2.92 & 1.20 & 10.16 & 2.48 \\
\hline \multirow{5}{*}{12.3} & A & 12.71 & 23.75 & 0.60 & 0.00 & 23.60 \\
\hline & B & 34.04 & 45.00 & 20.36 & 27.27 & 39.75 \\
\hline & $\mathrm{C}$ & 40.00 & 22.92 & 77.84 & 36.36 & 30.44 \\
\hline & $\mathrm{D}$ & 11.12 & 4.58 & 1.19 & 35.83 & 2.48 \\
\hline & $\mathrm{E}$ & 1.99 & 3.33 & 0.00 & 0.53 & 3.73 \\
\hline \multirow{5}{*}{12.4} & A & 16.82 & 25.83 & 6.59 & 9.09 & 22.98 \\
\hline & $\mathrm{B}$ & 36.16 & 45.83 & 32.94 & 18.18 & 45.96 \\
\hline & $\mathrm{C}$ & 34.04 & 20.42 & 60.48 & 39.03 & 21.12 \\
\hline & $\mathrm{D}$ & 10.86 & 4.17 & 0.00 & 32.62 & 6.83 \\
\hline & $\mathrm{E}$ & 1.98 & 3.33 & 0.00 & 1.07 & 3.10 \\
\hline \multirow[b]{3}{*}{12.5} & A & 22.65 & 27.92 & 2.99 & 32.09 & 24.22 \\
\hline & B & 30.99 & 41.66 & 11.38 & 24.60 & 42.86 \\
\hline & $\mathrm{C}$ & 40.00 & 23.33 & 83.23 & 34.23 & 26.71 \\
\hline \multirow{5}{*}{12.6} & A & 15.09 & 24.16 & 1.19 & 9.62 & 22.36 \\
\hline & B & 38.80 & 45.83 & 8.98 & 49.73 & 46.58 \\
\hline & $\mathrm{C}$ & 38.15 & 22.50 & 88.63 & 26.20 & 22.98 \\
\hline & $\mathrm{D}$ & 5.56 & 3.75 & 1.20 & 12.83 & 4.35 \\
\hline & $\mathrm{E}$ & 2.25 & 3.33 & 0.00 & 1.60 & 3.73 \\
\hline
\end{tabular}




\begin{tabular}{lllllll}
\hline Question Number & Option & Student Samples & A School & B School & C School & D School \\
\hline \multirow{4}{*}{12.7} & A & 21.20 & 28.34 & 17.37 & 12.30 & 24.85 \\
& B & 35.10 & 46.67 & 19.76 & 22.46 & 48.45 \\
& C & 37.88 & 17.50 & 62.28 & 56.15 & 21.74 \\
& D & 2.78 & 4.17 & 0.00 & 4.28 & 1.86 \\
& E & 3.05 & 3.33 & 0.60 & 4.82 & 3.10 \\
\hline
\end{tabular}

It can be seen from Table 9 that students believe that the effectiveness of physical inquiry experiment teaching is not good enough. Nearly half $(44.37 \%)$ of the students believe that their physical inquiry experiments are not effective. By conducting physical inquiry experiments, $43.97 \%$ of students think that their ability to Raise Questions do not improve significantly. 50.86\% of students see no significant improvement in their ability to Supposing and Assuming. 53.25\% of students think their ability to Making Plans and Designing Experiments has not improved clearly. $47.02 \%$ of the students believe that their ability to Conducting Experiments and Collecting Evidence do not improve obviously. $46.36 \%$ of students think their ability to Analyzing and Demonstrating are not improved significantly. $46.10 \%$ of students think their ability to Evaluating has not improved significantly. $43.70 \%$ of students believe that their ability to Communicating and Cooperating are not significantly improved.

The analysis results of the four schools are as follows. The percentages of people who think they have better effect on physical inquiry experiment are $72.5,25.15,51.88$ and 66.45 respectively. Through physical inquiry experiments, the percentage of students in the four schools who think their ability to Raising Questions improve significantly is 73.33, $11.98,59.89$ and 71.43 respectively. It can be seen that students of school B think that their ability to Raising Questions are not significantly improved, students of school A and school $\mathrm{C}$ think that their promotion is more obvious, and students of school D think they have a certain promotion. The percentage of people who have significantly improved their ability to Supposing and Assuming are 69.17, 22.75, 26.74 and 72.67 respectively. It can be seen that students in school B and school $\mathrm{C}$ think that their ability to Supposing and Assuming is not significantly improved, while students in school A and school D think that they have improved significantly. The percentage of people who think their ability to Formulating Plans and Designing Experiments has improved significantly are $68.75,20.96,27.27$ and 63.35 respectively. It can be seen that students of school $\mathrm{B}$ and school $\mathrm{C}$ think that their ability to Formulating Plans and Designing Experiments is not significantly improved, while students from school A and school D think their promotion is more obvious. The percentage of people who have significantly improved their ability to Conducting Experiments and Collecting Evidence is 71.66, 39.53, 27.27 and 68.94 respectively. It can be seen that students of school B and school $\mathrm{C}$ think their ability to Conducting Experiments and Collecting Evidence is not significantly improved, while students of school A and school D think their improvement is obvious. The percentages of people whose abilities of Analyzing and Demonstrating improve significantly are 69.58,
14.37, 56.69 and 67.08 respectively. It can be seen that students of school B think their ability to Analyzing and Demonstrating is not significantly improved, students of school A and school D think their improvement is obvious, and students of school $\mathrm{C}$ think they have certain improvement. The percentage of people whose Evaluating improved significantly was $69.99,10.17,59.35$ and 68.94 respectively. It can be seen that the students of B school think that their Evaluating promotion is not obvious. Students of school A and school D think that their promotion is more obvious, and students of school $\mathrm{C}$ think they have a certain promotion. The percentage of people who think their Communicating and Cooperating has improved significantly is 75.01, 37.13, 34.76 and 73.30 respectively. It can be seen that students of school B and school $\mathrm{C}$ think that their Communication and Cooperation are not significantly improved, while students of school A and school D think that they are significantly improved. According to the investigation on the implementation effect of physical inquiry experimental teaching, students in school B are the worst, students in school $\mathrm{C}$ are in poor condition, and students in schools A and D are the best. The reasons for the poor condition of students in B school are discussed in the preceding paragraph. Further investigation on the reasons for the poor effect of physical inquiry experiment teaching of students in school $\mathrm{C}$ shows that students in school $\mathrm{C}$ believe that less than half(47.59\%) of the students think their school is equipped with sufficient physical experiment equipment. And $41.18 \%$ believe their physics laboratory need to increase the degree of openness. What's more, the percentage of students who believe their physics teachers qualify for physical inquiry experiment teaching is the lowest compared with the other three schools (58.29\%). Less than half $(47.05 \%)$ are willing to do physical exploratory experiments. These subjective and objective reasons may also lead students to believe that the implementation effect of their own physical inquiry experiment teaching is not good enough.

\section{Conclusions}

The present situation of experimental teaching of physical inquiry is not optimistic and needs to be improved. The majority of students have a positive intention to carry out experimental teaching of physical inquiry. However, there are many problems in the implementation conditions, the implementation process and the implementation effect of physical inquiry experiment teaching. To a certain extent, it falls into the practical dilemma of formalism.

Both the physics curriculum standard and the teaching materials have put forward clear requirements for cultivating students' experimental and exploratory ability. However, due 
to the influence of the exam-oriented education under the college entrance examination system, both teachers and students focus on the college entrance examination. So it is difficult to carry out exploratory experimental teaching in a substantive way [5].

\section{Implications}

It is found in the questionnaire and interview that some schools do not implement or seldom carry out experimental teaching, and students seldom have the opportunity to conduct hands-on experiments. Most of the schools have completed all the new courses in senior one and sophomore year. The third year is full of reviewing and drilling before the national college entrance examination [6]. To some extent, inquiry experiment teaching falls into the practical dilemma of formalism. This phenomenon should arouse the attention of all sectors of society. It is worthwhile to further explore the origin and underlying causes of these problems. All sectors of society should work together to gradually improve and perfect the implementation and evaluation mechanism of exploratory experimental teaching in science.

\subsection{Provide Multiparty Support for Effective Implementation of Inquiry Experiment Teaching}

The survey results show that physical inquiry experiment teaching needs further improvement. To promote efficient implementation and perfection of physics inquiry experiment teaching, it is suggested to provide teachers with more theoretical and practical support for exploratory experimental teaching. Besides, it is necessary to further improve the implementation conditions of inquiry experiment teaching and increase the teaching hours of physical inquiry experiment and the proportion of inquiry experiment teaching.

\subsubsection{Provide Teachers with More Theoretical and Practical Support for Inquiry Experimental Teaching}

Through the form of academic exchange, special report, open course of inquiry experiment teaching, and the competition of exploratory experimental teaching skills, the teachers are trained in exploratory experiment teaching. Teachers are encouraged to exchange exploratory experimental teaching experience with other teachers in the same schools. The schools actively employ relevant experts to guide teachers, help teachers to interpret the requirements of the curriculum standards and teaching materials, and provide teachers with exploratory experimental cases and other resources to develop physical inquiry teaching [7]. Create an atmosphere that attaches great importance to exploratory experimental teaching and provide teachers with more theoretical and practical support for exploratory experimental teaching.

\subsubsection{Promote Implementation Conditions of Exploratory Experimental Teaching}

Survey results show that the majority physical inquiry experiment is carried out in groups of three or four students, which is obviously higher than the number of students (1-2 people) in countries with relatively good international practice ability when conducting exploratory experiments [8]. Therefore, it is necessary to attach importance to the group experiment and classroom experiment, and combine exploratory teaching to cultivate students' operational ability and to enable students to understand and grasp the concepts through observation, analysis and induction [9]. It is suggested that more funds should be invested in the research experiment, and the equipment of physical laboratory and physical experimental instruments should be improved. At the same time, increasing the openness of physics laboratories will enable students who are willing to explore more opportunities to do experiments. And it will be helpful for the further opening of the laboratory to strengthen the students' awareness of loving experimental instruments. The experimental teaching community is established among schools. The exploratory experimental teaching equipment and experimental equipment can be shared among different schools, so as to achieve the goal of saving money and promoting communication.

\subsubsection{Increase the Teaching Time and the Teaching Proportion of Inquiry Experiment}

Scientific inquiry is the learning goal that students must achieve in order to complete the physics course. Therefore, physical experiment and scientific inquiry are put together to raise ability requirements in the curriculum standard. The seven elements of scientific inquiry are not necessarily covered in a single physics class. The cultivation of experiment and inquiry ability should be considered in a long time and space, which can be carried out in multiple classes [10].

The results of the survey show that students think their abilities of Raising Questions, Supposing and Assuming, Formulating Plans and Designing Experiments are not significantly improved through exploratory experimental teaching. This is directly related to the relatively small proportion of exploratory experiments and the relatively large proportion of confirmatory experiments in the current teaching of science experiments. It is well known that the ability to Raise Questions, the ability to Suppose and Assume, and the ability to Formulate Plans and Design Experiments are of great importance to the cultivation of students' innovation ability. And it will play an important role in laying the foundation for students to make major breakthroughs in relevant fields after they enter the society. In the basic education stage, attention should be paid to cultivating students' innovative consciousness, innovative mind and innovative ability. The proportion of physical inquiry experiment class and inquiry experiment teaching in science teaching should be appropriately increased. Students are encouraged to establish a community of physical inquiry experiment learning and actively discuss inquiry experiment in extracurricular time. The scientific inquiry and experimental ability of students should be included in the important examination evaluation category. This will 
fundamentally eliminate the concerns of teachers and students, making them carry out exploratory experimental teaching at ease and boldly. Thus, they are willing to spend energy and time to improve the implementation process and effect of exploratory experiment teaching.

\subsection{Add Experimental Operation Test to High-stakes Test Evaluation}

The new round of basic education curriculum reform advocates scientific inquiry, and the requirement of scientific inquiry ability is an important part of science curriculum standard. According to the analysis of the physics proficiency test papers and the college entrance examination paper, the examination questions involving students' scientific inquiry and physical experiment ability are few or missing. In view of the fact that the paper-and-pencil test can mainly check students' knowledge mastery and the examination of the students' scientific inquiry and the physical experimental ability are limited, it is suggested to increase the authenticity evaluation method in the high-stakes examination. The survey results show that the majority of students are in favor of adding real experimental operation tests in the college entrance examination and the physics academic proficiency test [11]. At the same time, with further strengthening of the authority and applicability of academic level examination, increasing the authenticity evaluation method can effectively guide the further development of curriculum reform. The Ministry of Education has made it clear in the academic level examination documents that it will require the experimental operation of relevant subjects [12]. Therefore, it is suggested to increase the experimental operation test in the science academic level examination. Every province should actively explore the effective way to implement the experiment operation test, so as to ensure the credibility and authoritative of the experiment operation test. With the effective implementation of the academic proficiency test and the accumulation of successful experience, it is suggested that the real scientific inquiry and experimental operation should be added to the college entrance examination and the proportion of the experiment will be increased gradually, so as to effectively promote the students' creative thinking and practical ability in the basic education stage.

\subsection{Improve the Professional Quality of Physics Teachers}

Teachers are organizers and leaders of teaching activities [13]. Inquiry experiment teaching requires teachers to be good at guiding students to participate actively in experiment teaching. Therefore, the comprehensive quality of physics teachers is directly related to the effectiveness of inquiry based experimental teaching.

\subsubsection{Create a Physical Situation to Stimulate Students to Participate in the Inquiry}

Physical situation is a situation with physical knowledge and physical thinking method [14]. It is the background of the emergence of physical knowledge and an important prerequisite for finding and putting forward physical problems.
Only when the created physical situation enters the "nearest development zone" and the content is challenging and exploratory can the students stimulate their desire for exploration on the basis of the existing cognition [15]. In the physical situation, it is helpful to cultivate students' good habits of mind and scientific learning methods and to change the situation where the attention is only directed to physical knowledge, so as to achieve the purpose of improving teaching quality.

\subsubsection{Take the New Curriculum Reform as the Reference and Change the Traditional Teaching Concept}

The new curriculum reform emphasizes the cultivation of students' subjective initiative, and the inquiry-based experiment teaching thinks highly of the exertion of students' practical ability and initiative ability, both of which are completely consistent with each other [16]. Therefore, in the process of physics teaching, teachers should take the new curriculum reform as the benchmark, change the traditional teaching concept, constantly create conditions for students to create exploratory experimental teaching courses, and attach importance to the cultivation of experimental skills.

\section{Acknowledgements}

Special thanks should go to the guidance provided by Professor Lei Bao of Ohio State University in thesis writing. Thanks to Xiaoxia Chen, Ge Qin and Zhenyan Feng of the School of Education of Qufu Normal University for the support of literature collection and data processing. In addition, this research is supported by the Ministry of Education's Humanities and Social Science Research Youth Foundation Project "The Construction and Application of the Quality Evaluation Index System of the Academic Level Examination in Ordinary High School"(16YJC880073), The Youth Topic of the National Education Science Planning Ministry of Education "The Construction and Practice Research of the Consistency Evaluation Index System of Teaching and Curriculum Standards"(EHA140392), Research on the Evaluation Index System of the Consistency of the High School Academic Level Examination and the Curriculum Standard in the Post Doctoral Science Foundation of China(2017M612318) and Research and Planning Project of Philosophy and Social Science of Qufu Normal University "Study on the Consistency Analysis Model of High School Academic Level Examination and Curriculum Standard" (XSK201602).

\section{References}

[1] Ministry of Education. Physics curriculum standard of senior high school (Draft) [S]. Beijing: People's Education Press, 2003:10-11.

[2] Song Shujie. New curriculum concept and teaching practice of senior high physics [M]. Beijing: Commercial Press, 2006, 94. 
[3] Xu Lijun. Exploratory experimental teaching research of high school physics [D]. Jiangxi normal university, 2007, 3.

[4] Liao Boqin, Jiang Tao. The development and guidance of the Physics inquiry activity [M]. Nanjing: Jiangsu Education Press. 2012: 18-19, 35.

[5] Wang Jiaoguo, Ma Yapeng. A comparative study on the characteristics of Physics textbooks in senior high school-Take "PEP Edition" and "Ian Edition" of Physical Book 1 as an example [J]. Journal of Inner Mongolia Normal University (Education Science Edition), 2008(8): 128-134.

[6] Song Weizhen, Zhang Yao. Psychological test [M]. Beijing: Science Press. 1987: 239-243.

[7] Zheng Richang. Psychological measurement [M]. Changsha: Hunan Education Press, 1987: 427-433.

[8] JRV Flora, AT Cooper. Incorporating Inquiry-Based Laboratory Experiment in Undergraduate Environmental Engineering Laboratory [J]. Journal of Professional Issues in Engineering Education and Practice, 2005, 131(1): 19-25.

[9] Hou Dan, Yi Hangyu. Types and thought of physics inquiry experiment activities in senior high school [J]. Teaching and Management, 2015(21):111-114.

[10] Liu Bingsheng. Go into the new curriculum reform in senior high school: Physics teachers must read [M]. Nanjing: Nanjing Normal University Press, 2005: 185.
[11] Q Zhou, J Guo, Y Wang. Promoting preservice teachers' critical thinking skills by inquiry-based chemical experiment [J]. Procedia-Social and Behavioral Sciences, 2010, 2(2): 4597-4603.

[12] Ministry of Education of the People's Republic of China (2014) The Ministry of education's opinions on the implementation of general high school academic proficiency test [EB/OL]. http://www.moe.edu.cn/publicfiles/business/htmlfiles/moe/s45 59/201412/181664.html.

[13] Yin Hanqing. Research on the choice of inquiry points in physics inquiry teaching in senior high school [J]. Educational Theory and Practice, 2015(14):53-55.

[14] Wang Aihong. On the design and implementation strategy of physics demonstration experiment in senior high school [J]. Physics Teaching Reference in Middle School, 2015(12):25.

[15] Wang Zhihui. On the adaption of physics experiment in senior middle school [J]. Physics Teaching Reference in Middle School, 2017(7X):27-28

[16] Zhu Xiaohui. Characteristics of scientific inquiry course under the new curriculum concept---Take physics teaching in senior middle school as an example [J]. Educational Theory and Practice, 2017(2):58-59. 